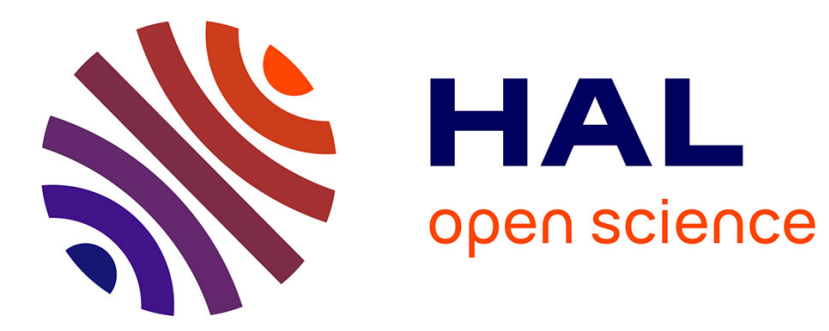

\title{
DEET microencapsulation: a slow-release formulation enhancing the residual efficacy of bed nets against malaria vectors
}

Raphael N'guessan, Bart G J Knols, Cedric Pennetier, Mark Rowland

\section{- To cite this version:}

Raphael N'guessan, Bart G J Knols, Cedric Pennetier, Mark Rowland. DEET microencapsulation: a slow-release formulation enhancing the residual efficacy of bed nets against malaria vectors. Transactions of The Royal Society of Tropical Medicine and Hygiene, 2007, 102 (3), pp.259-262. 10.1016/j.trstmh.2007.10.012 . hal-03248978

\section{HAL Id: hal-03248978 https://hal.science/hal-03248978}

Submitted on 10 Jun 2021

HAL is a multi-disciplinary open access archive for the deposit and dissemination of scientific research documents, whether they are published or not. The documents may come from teaching and research institutions in France or abroad, or from public or private research centers.
L'archive ouverte pluridisciplinaire HAL, est destinée au dépôt et à la diffusion de documents scientifiques de niveau recherche, publiés ou non, émanant des établissements d'enseignement et de recherche français ou étrangers, des laboratoires publics ou privés. 


\section{Title}

Deet microencapsulation: a slow release formulation enhancing the residual efficacy of bednets against malaria vectors

\section{Authors and affiliation}

Raphael N’Guessan ${ }^{\mathrm{a}, \mathrm{b}}$, Bart G.J. Knols ${ }^{\mathrm{c}}$, Cedric Pennetier ${ }^{\mathrm{b}, \mathrm{d}}$ and Mark Rowland ${ }^{a}$

${ }^{a}$ London School of Hygiene and Tropical Medicine, London, UK

${ }^{b}$ Centre de Recherche Entomologique de Cotonou (CREC), Cotonou, Benin

${ }^{c}$ Wageningen University \& Research Centre, Laboratory of Entomology, The Netherlands

${ }^{d}$ Institut de Recherche pour le Developpement (IRD), Cotonou , Benin

\section{Summary}

Textile materials treated with synthetic repellents have the potential to provide protection against insect disease vectors but lack the residual activity necessary to achieve a prolonged effect or be cost effective. Deet $\mathrm{MC}$ is a formulation of deet ( $\mathrm{N}, \mathrm{N}$ diethyl-m-toluamide) in which the repellent is gradually released from a capsule that binds the repellent. An experiment carried out on deet treated mosquito netting showed that the formulation repels, inhibits blood-feeding and kills mosquitoes for a period of at least 6 months under laboratory conditions.Such formulations have potential on nets against pyrethroid resistant mosquitoes or on clothing or bedding materials distributed in emergencies or refugee camps.

Keywords: Deet , microencapsulation, Anopheles, bednets, efficacy

\section{Introduction}

Resistance to pyrethroid insecticides has become increasingly widespread in the malaria vector Anopheles gambiae in western and eastern Africa and in An. funestus in southern Africa (Chandre et al., 1999; Hargreaves et al., 2000; Vulule et al., 1999). The recent failure of insecticide treated nets (ITNs) and indoor residual spraying (IRS) to kill or protect against pyrethoid resistant An. gambiae in southern Benin (N'Guessan et al., 2007) means that identifying alternative insecticides and repellents to supplement or replace the pyrethroids has become very urgent (Zaim and Guillet, 2002). A recent study involving impregnation of nets with deet repellent conducted in experimental huts in Ivory Coast indicated that this is a promising approach to overcoming the problems associated with pyrethroid-resistant mosquitoes and potentially prevent malaria (N'Guessan et al., 2006). Deployed on fabric rather than as topical skin treatment, deet acted not only as a conventional insect repellent but also as a toxicant, killing the majority of pyrethroidresistant $A n$. gambiae and $C x$. quinquefasciatus mosquitoes that entered the huts. The formulation of deet tested was a water-miscible lotion. Being inherently volatile any effect of deet on mosquitoes was lost after 2-3 weeks. 
In the era of long-lasting insecticidal nets any formulation that needed such frequent replenishment is unlikely to find favour even in places where pyrethroids are no longer effective. Advances in formulation technology has been an important driver leading to long-lasting insecticidal nets. Microencapsulation technology, in which the active ingredient is enclosed within a polymer capsule and gradually leaches to the outside, is one way in which residual activity of insecticides may be prolonged. Microcapsule suspensions of pyrethroids are now entering the market as long-lasting indoor residual spray treatments (WHO, 2007). In order for deet to become viable as a textile treatment the repellent will need to be bound within some kind of longlasting formulation. Sumitomo Corporation has recently developed a microencapsulated formulation of deet in which the active ingredient diffuses slowly through a polymer membrane over a period of months. Human contact or friction with the treated fabric is believed to accelerate the diffusion process. To examine its potential as a fabric or net treatment, the microencapsulated deet was applied to polyester netting and tested against $A n$. gambiae in laboratory tunnel tests over several months (WHO, 2006). A topical formulation of deet on netting served as a control.

\section{Material and methods}

\subsection{Deet MC}

Deet $\mathrm{MC}$ is a $30 \%$ aqueous suspension of $\mathrm{N}, \mathrm{N}$ diethyl-m-toluamide enclosed in a melamine microcapsule, produced by Sumitomo Corporation, Tokyo,

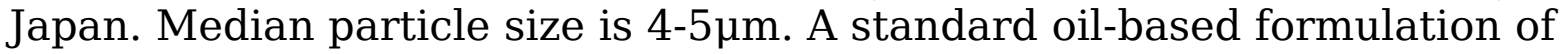
deet $30 \%$ was produced by Osler ${ }^{\circledR}$, France. Both formulations were diluted in water and applied at $8 \mathrm{~g}$ deet $/ \mathrm{m} 2$ on 100 denier polyester netting (N'Guessan et al., 2006; Pennetier et al., 2007) The netting samples were first tested $72 \mathrm{hrs}$ after treatment and re-tested at intervals over 6 months. The netting samples were left unwrapped between tests.

\subsection{Tunnel tests}

Tunnel tests were undertaken with an insecticide susceptible laboratory strain Kisumu of An. gambiae in Benin. They have been described and used widely (Chandre et al., 2000 ; N'Guessan et al., 2007a,b). The tunnel test is a laboratory system designed to simulate many of the behavioural and toxicological interactions that occur with host-seeking mosquitoes. Tunnel tests are done as a forerunner to experimental hut trials, and provide information on repellency, blood-feeding inhibition and mortality. The equipment consists of a square glass cylinder $(25 \mathrm{~cm}$ high, $25 \mathrm{~cm}$ wide, $60 \mathrm{~cm}$ long) which is divided into two chambers by a netting-covered frame that slots across the tunnel (WHO, 2006). In one of the chambers, a guinea pig is housed unconstrained in an open meshed cage and in the other chamber, 100 unfed female anopheline mosquitoes aged 2-5 days are released at dusk and left overnight. The netting is deliberately holed with nine $1 \mathrm{~cm}$ holes to give opportunity for mosquitoes to pass into the baited room. The following 
morning, the number of mosquitoes found live or dead, fed or unfed in each chamber is scored. Live mosquitoes are given access to sugar solution, and monitored up to $24 \mathrm{hrs}$ to score delayed mortality. For 3 each repellent formulation, two replicates of each 100 mosquitoes were conducted in the tunnel.

\subsection{Data analysis}

A chi-square test was performed to assess trend in residual efficacy of treatments over time.

\section{Results}

The effects of the deet treatments on penetration, blood-feeding and mortality rates are shown in figure 1 . The unencapsulated formulation inhibited $80 \%$ of the mosquitoes from penetrating the holed netting when freshly applied, and over 3-6 months the proportion penetrating decreased significantly from $40 \%$ to $10 \%(\mathrm{P}=0.001)$, which was the same rate observed in the untreated control (fig. 1A). With the microensapsulated formulation passage inhibition was only $40 \%$ initially and remained at this level over the full 6 months $(\mathrm{P}=0.11)$. Initially, inhibition of bloodfeeding was $100 \%$ with the unencapsulated formulation, decreasing to $70 \%$ at 3 months and to complete loss of activity between 3 and 6 months (fig 1B). Interestingly, protection from the microcapsule increased after 1 month and reached a maximum at 6 month, suggesting that a higher concentration of active ingredient was present on the surface of the capsules after this interval. With the unencapsulated formulation, mortality was $100 \%$ initially but showed exponential decay over the 6 months ( $<<0.001$ ) (Fig 1 C). Mortality rates with deet MC remained between $82 \%$ and $65 \%$ throughout, showing a gradual though significant decay in performance $(P=0.03)$.

\section{Discussion}

Applied to skin, conventional formulations of deet persist for several hours. Applied to textiles or netting topical formulations may persist to good effect for1-3 months. Evaporation or absorption rates on textiles are clearly a lot slower than on skin. The mode of contact with host-seeking mosquitoes may differ too. With skin application mosquitoes are deterred from alighting on the host by a vapour layer of repellent (Debboun et al., 2006). With textile and net applications the mosquitoes make tarsal contact with the treated surface. This route of pick up is clearly sufficient for deet to exert a toxic effect as has been shown in several recent studies on mosquitoes and other insects in laboratory and field experiments (N'Guessan et al., 2006 ;

Pennetier et al., 2005 ; Licciardi et al., 2006). Microcapsule particles would adhere to tarsi, as is known to occur with encapsulated insecticide formulations, and would continue to act upon the insect whether or not it took evasive action from the repellent treated surface.

Microencapsulation has the capacity to greatly prolong the persistence of volatile repellents and to change the way in which we use them for 
protection. The experiment on netting described here shows that microencapsulated deet acquires some of the characteristics of residual insecticides, showing a combination of repellent, toxic and feeding inhibition properties, and persistence 4 of activity for several months. The protective effect against biting of An.gambiae was superior to that shown by the residual pyrethroid insecticides permethrin (Corbel et al., 2004) and deltamethrin (Hougard et al., 2003) tested under similar conditions. The formulation is long lasting in the sense of prolonged residual activity but not long lasting as meant by long-lasting insecticidal nets (LLIN) which are nets that remain insecticidal despite repeated washing (WHO, 2005a). The deet microcapsule is not designed to be wash resistant. That would require further additives such as the chemical binders applied in LLIN technology. That would be a useful next step to take towards a long-lasting repellent treated net (LLRN) to use against pyrethroid resistant vectors. Further advanced test of bednets treatred with Deet MC-in experimental huts is needed to ascertain their personal protection under natural condition. The current deet microcapsule formulation may have potential in a number of situations where protection is required for a period of months and where washing is infrequent. For outbreaks of dengue transmitted by day-active Aedes aegypti mosquitoes the deet might be applied to clothing or domestic fabrics such as curtains. For epidemics of malaria or in refugee situations where people are sleeping outdoors or in makeshift shelters, the deet microcapsule might be used to treat the blankets or sheets that are distributed by aid agencies in such emergencies. Experience has shown that insecticide treated nets are not necessarily appropriate in emergencies (WHO, 2005b) whereas repellent-treated blankets would not require behavioural change of users to be used to good effect.

Funding: The study was supported by the Gates Malaria Partnership of the London School of Hygiene and Tropical Medicine

\section{Conflict of interest:}

The authors have no conflict of interest regarding the work reported in this paper

\section{Authors contribution:}

$\mathrm{RN}$ and MR conceived the study protocol ; $\mathrm{RN}$ did the analysis interpreted and wrote the manuscript. BK read and revised the manuscript critically ; $\mathrm{CP}$ read and revised the manuscript ; MR revised the paper substantially for intellectual content and approved the final manuscript. $\mathrm{RN}$ is guarantor of the paper.

\section{Acknowledgement}

We wish to thank Boko P. and Odjo A. for valued technical assistance. We are very greateful to Mr Takanori Ando of Sumitomo Corporation, Agriscience, Tokyo, for providing the Deet MC formulation and technical 
advice. Thanks also go to Dr Jean Marc Hougard of Institut de Recherche pour le Development, Cotonou, Benin for providing the normal Deet for comparison.

\section{References}

Chandre, F., Darriet, F., Duchon, S., Finot, L., Manguin, S., Carnevale, P., Guillet, P., 2000. Modifications of pyrethroid effects associated with kdr mutation in Anopheles gambiae. Med Vet Entomol. 14: 81-8.

Chandre, F., Darriet, F., Manga, L., Akogbeto, M., Faye, O., Mouchet, J., Guillet, P., 1999. Status of pyrethroid resistance in Anopheles gambiae sensu lato. Bull. World Health. Org. 77, 230-234.

Corbel, V., Chandre, F., Brengues, C., Akogbeto., Lardeux, F., Hougard, J.M., Guillet,.2004. Dosage-dependent effects of permethrin-treated nets on the behaviour of Anopheles gambiae and the selection of pyrethroid resistance. Malaria J. 3, 22.

Debboun, M., S. P. Frances, and D. Strickman. 2006. Insect repellents: principles, methods, and uses. CRC Press, Taylor \& Francis Group.

Hargreaves, K., Koekemoer, L.L., Brooke, B., Hunt, R.H., Mthembu, J., Coetzee, M., 2000. Anopheles funestus resistant to pyrethroid insecticides in South Africa. Med. Vet. Entomol. 14, 181-189.

Hougard, J. M., Duchon, S., Darriet, F., Zaim, M., Rogier, C., Guillet, P., 2003. Comparative performances, under laboratory conditions, of seven pyrethroid insecticides used for impregnation of mosquito nets. Bull. World Health Organ. 5, 324-333.

Licciardi, S., Herve, J.P, Darriet, F., Hougard, J.M., Corbel, V., 2006. Lethal and behavioural effects of three synthetic repellents (DEET, IR3535 and KBR 3023) on Aedes aegypti mosquitoes in laboratory assays. Med Vet Entomol. 20, 288-293.

N’Guessan, R., Rowland, M., Moumouni TL., Kesse, B., Carnevale, P., 2006. Evaluation of synthetic repellents on mosquito nets in experimental huts against insecticide-resistant Anopheles gambiae and Culex quinquefasciatus mosquitoes. Trans. R. Soc. Trop. Med. Hyg. 100, 1091- 1097.

N’Guessan, R., Corbel, V., Akogbéto, M., Rowland, M., 2007. Reduced efficacy of Insecticide treated nets and Indoor residual spraying for malaria control in pyrethroid resistance area, Benin. Emerg. Inf. Dis. 13, 199-206.

N'Guessan, R., Corbel, V., Bonnet, J., Yates, A., Asidi, A., Boko, P., Odjo, A.,Akogbeto, M., Rowland M., 2007a. Evaluation of indoxacarb, an 
oxadiazine insecticide for the control of pyrethroid-resistant Anopheles gambiae (Diptera: Culicidae). J Med Entomol. 44: 270-276.

N'Guessan, R., Boko P., Odjo, A., Akogbeto, M., Yates, A., Rowland, M.,2007b. Chlorfenapyr: a pyrrole insecticide for the control of pyrethroid or DDT resistant Anopheles gambiae (Diptera: Culicidae) mosquitoes. Acta Trop. 102:69-78.

Pennetier, C., Corbel, V., Hougard, J.M,. 2005. Combination of a nonpyrethroid insecticide and a repellent: a new approach for controlling knockdown-resistant mosquitoes. Am. J. Trop. Med. Hyg. 72, 739-744.

Pennetier , C., Corbel, V., Boko, P., Odjo, A., N'Guessan, R., Lapied, B., Hougard, J.M., 2007. Synergy between repellents and non-pyrethroid insecticides strongly extends the efficacy of treated nets against Anophelesgambiae Malar J. 29, 6-38.

Vulule, J.M., Beach, R.F., Atieli, F.K., McAllister, J.C., Brogden, W.G., Roberts, J.M., Mwangi, R.W., Hawley, W.A., 1999. Elevated oxidase and esterase levels associated with permethrin tolerance in An. gambiae from Kenyan villages using permethrin-impregnated nets. Med. Vet. Ent. 13, 239-244.

WHO (2005a). Guidelines for laboratory and field testing of long-lasting insecticidal mosquito nets. WHO/CDS/WHOPES/GCDPP/2005.11.

WHO (2005b). Malaria control in complex emergencies: an inter-agency field handbook. WHO/HTM/MAL/2005.1107.

WHO (2006). Guidelines for testing mosquito adulticides for indoor residual spraying and treatment of mosquito nets. WHO/CDS/NTD/WHOPES/GCDPP/ 2006.3

WHO (2007). Report on the tenth WHOPES working group meeting.WHO/CDS/NTD/WHOPES/ 2007.1

Zaim, M., Guillet, P., 2002. Alternative insecticides: an urgent need. Trends Parasitol. 18, 161-163.

\section{Figure captions}

Fig. 1. Efficacy of netting treated with Deet MC (encapsulated formulation) and oil-based formulated formulation of Deet against An. gambiae in tunnel tests: 
(A) Inhibition of penetration through the netting (repellency). (B) Bloodfeeding inhibition reates, (C) Mortality rates after 24h holding period.

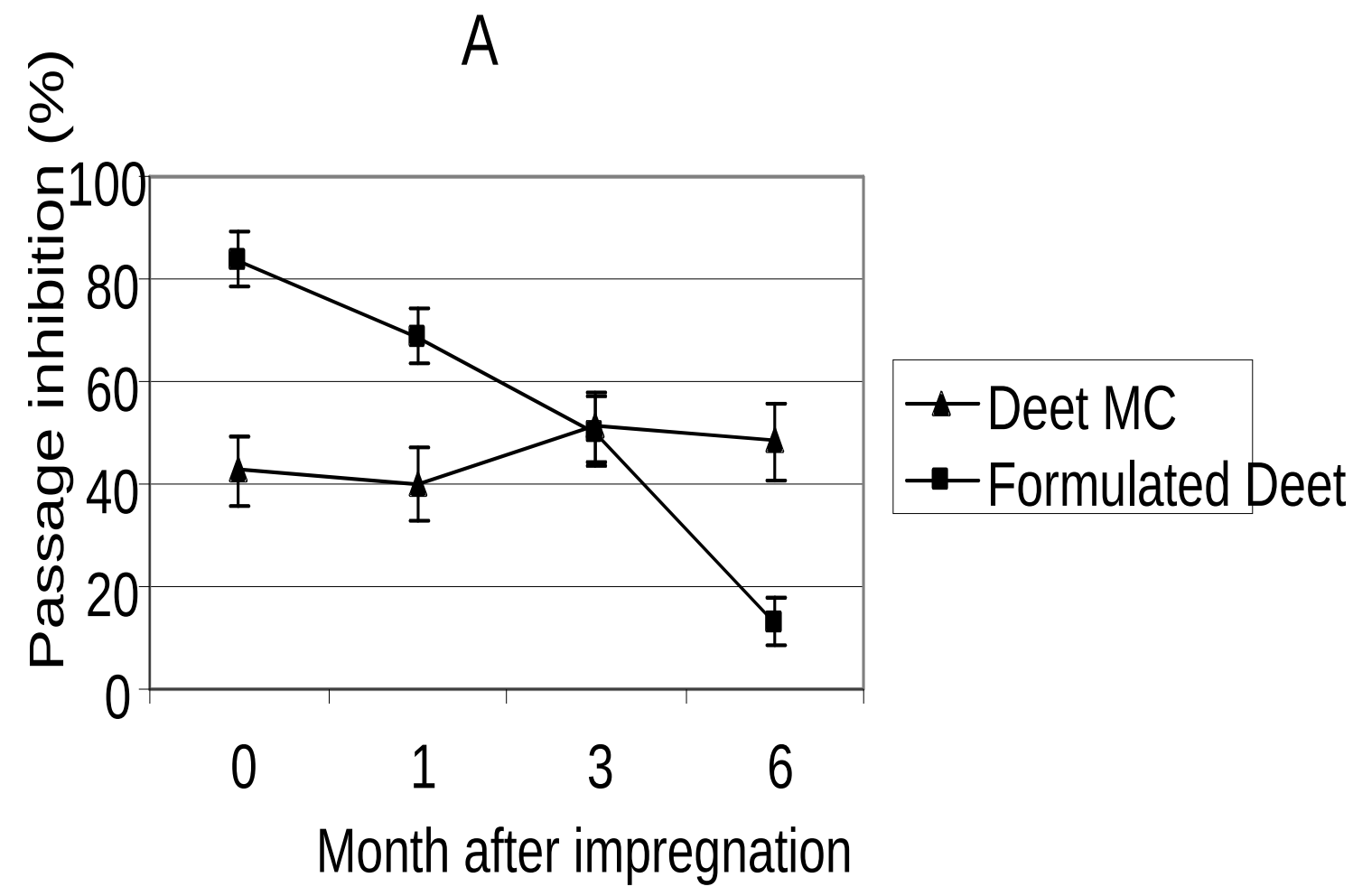




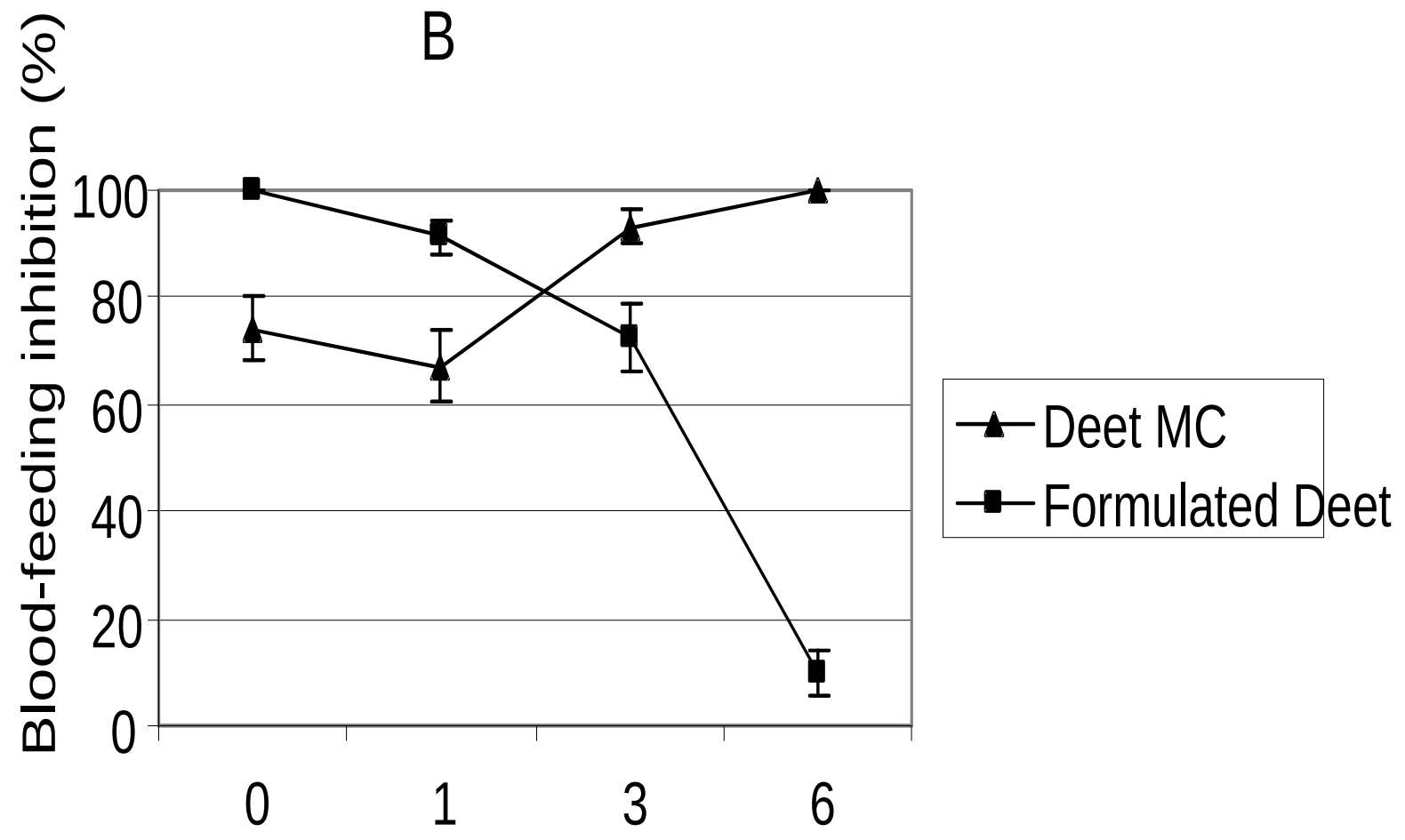

Month after impregnation

C

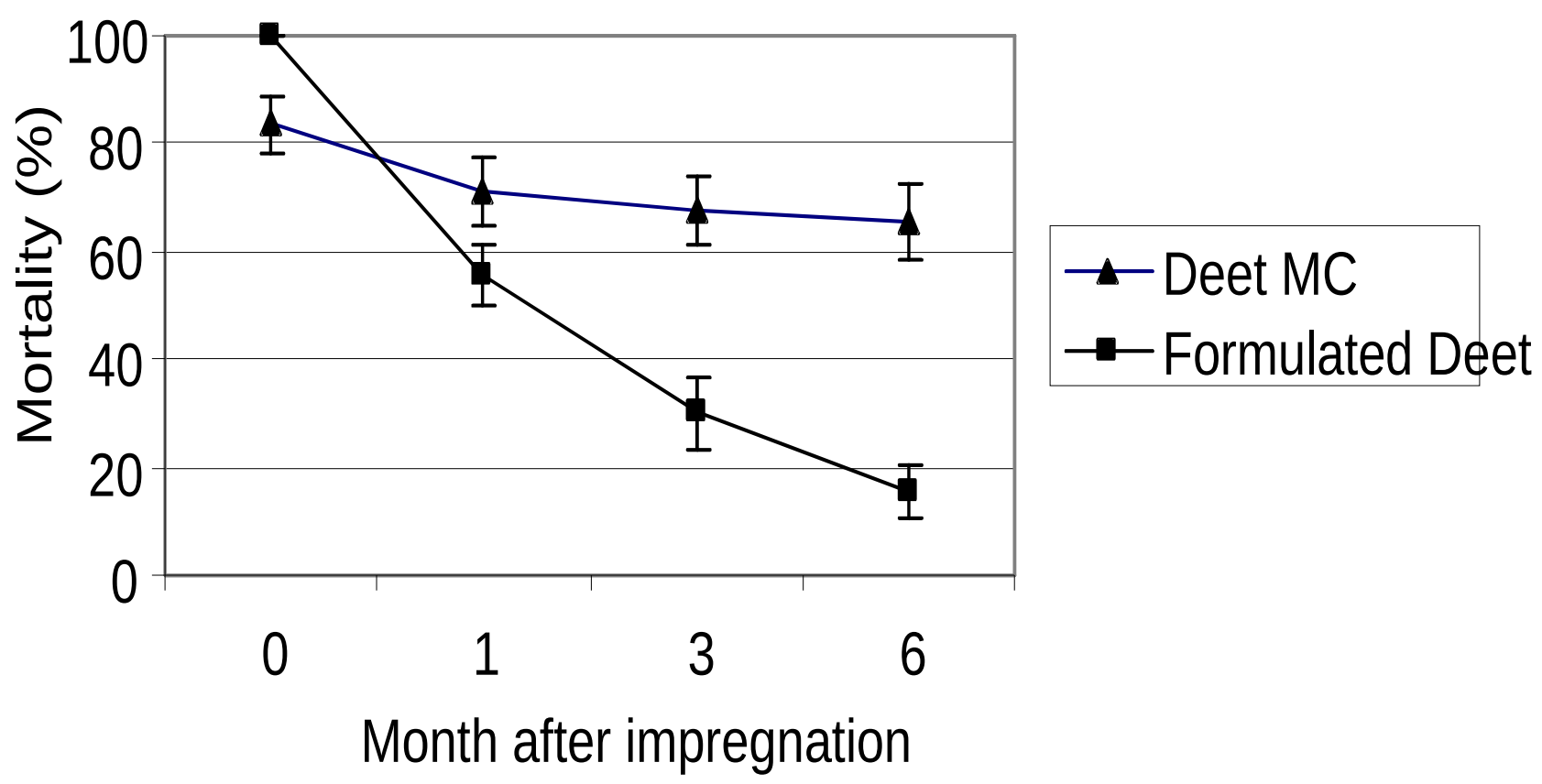

